\title{
O CONSELHO NACIONAL DE SECRETÁRIOS DE EDUCAÇÃO NA REFORMA EDUCACIONAL DO GOVERNO FHC
}

\author{
Márcia Ângela da S. Aguiar
}

\begin{abstract}
RESUMO: Aborda-se, neste texto, a atuação do Conselho Nacional dos Secretários de Educação (CONSED), entidade que reúne os titulares das secretarias de educação dos estados brasileiros, destacando a sua influência na formulação e execução das políticas governamentais voltadas para a educação básica, no contexto da reforma educacional em curso no país. Focalizam-se as relaçōes que foram estabelecidas entre as instâncias da União e dos estados, na área educacional, privilegiando o Executivo federal, representado pelo Ministério da Educação (MEC), e a representação dos secretários estaduais de Educação - o Conselho Nacional dos Secretários de Educação (CONSED), ao longo do período de 1995 a 1998. Explorase a idéia, com base numa pesquisa documental, de que, durante o primeiro governo de FHC, acentuou-se a aproximação do CONSED com o MEC, atenuando-se os conflitos entre essas instâncias e ampliando-se a influência do Executivo federal na condução das políticas educacionais.
\end{abstract}

Palavras-chave Política educacional. Conselho Nacional dos Secretários de Educação (CONSED). Avaliação de políticas. Gestão educacional.

The Brazilian Council of Education Secretaries in the educational reform under Mr. Fernando Henrique CARDOSO'S ADMINISTRATION

ABSTRACT: This paper approaches the role of the Conselho Nacional dos Secretários de Educação (CONSED), which gathers the secretaries of the Brazilian Education State Departments, highlighting its influence on the formulation and execution of national policies for elementary

Doutora em Educação pela Universidade de São Paulo (USP), professora do Centro de Educação e do Programa de Pós-Graduação em Educação da Universidade Federal de Pernambuco (UfPE) e coordenadora do Grupo de Trabalho "Estado e Política Educacional" da Associação Nacional de Pós-Graduação e Pesquisa em Educação (ANPEd). E-mail: marcia_angela@uol.com.br 
education in the context of the educational reform occurring in Brazil. It focuses the relationships built up between Federal and States authorities in the educational area, relationships that privileged the Federal Executive, represented by the Department of Education (MEC) and the Educational State Department representatives - The Conselho Nacional dos Secretários de Educação (CONSED), during the 1995-1998 period. Based upon a documental research, the text explores the idea that Fernando Henrique Cardoso's first Government straightened the links between CONSED and the Department of Education, in order to attenuate the conflicts involving both authorities and increase the influence of the Federal Executive on the conduction of the Educational Policies.

Key words: Educational Policies; Conselho Nacional dos Secretários de Educação (CONSED); Policies Assessment; Educational Administration.

$\mathscr{P}$ ode-se considerar, à luz dos estudos existentes na área, que a reforma educativa no Brasil tomou forte impulso no primeiro governo de Fernando Henrique Cardoso (1995-1998), configurando-se como uma das faces da reforma do Estado neste campo. Com o propósito de tornar o Estado "ágil e produtivo", o governo editou uma série de medidas de política, entre as quais tem singular destaque a instituição do Ministério da Administração Federal e da Reforma do Estado (MARE), que foi o centro condutor da reforma administrativa. Demonstrava o governo, com esse tipo de iniciativa, a clara intenção de estabelecer as condiçóes estratégicas necessárias à implementação de importantes mudanças no aparato estatal com repercussóes em todas as esferas da sociedade. No âmbito dessas mudanças, sobressaem-se as alterações que serão efetivadas no Ministério da Educação (MEC) visando a adequar a estrutura técnicoadministrativa aos novos objetivos governamentais. A idéia central seria facilitar o desenvolvimento de ações no sentido de proceder a uma profunda reforma no sistema educacional, reestruturar a máquina burocrática, bem como incentivar a sociedade civil a colaborar com o projeto de modernização do país.

Concomitantemente às alteraçôes, de cunho técnico-burocrático, processadas no aparato organizacional do MEC, serão instauradas novas formas de relacionamento entre as instâncias jurídicoadministrativas, em decorrência, sobretudo, das disposiçóes estabelecidas na Constituição federal de 1988. Como se sabe, a Constitui- 
ção federal não só amplia o rol das competências concorrentes entre União, estados e municípios como atribui a estes novas competências. São descentralizados atribuiçóes e recursos dos entes federativos num cenário em que "as ambigüidades e as competências indefinidas não fazem senão acentuar os desequilíbrios fiscais e aumentar as zonas de incerteza quanto à distribuição de responsabilidades. Embora haja certa tendência à descentralização política e a uma radicalização da Federação, são visíveis as dificuldades do governo federal para reduzir suas funçōes" (Jacobi, 2000, p. 43).

Ao que parece, mesmo quando aponta para uma descentralização das políticas de educação, o governo federal e sua burocracia vão ampliando o grau de interferência na definição e operacionalização das políticas dos estados e municípios, mediante o estabelecimento de diversas formas e mecanismos de controle.

No presente texto, focalizam-se as relaçôes que, ao longo do período de 1995 a 1998, foram estabelecidas entre as instâncias da União e dos estados, notadamente na área educacional, privilegiando o Executivo federal, representado pelo Ministério da Educação (MEC), e a representação dos secretários estaduais de Educação - o Conselho Nacional dos Secretários de Educação (CONSED). ${ }^{1}$ Explora-se a idéia, com base numa pesquisa documental, ${ }^{2}$ de que, durante o primeiro governo de FHC, acentuou-se a aproximação do CONSED com o MEC, atenuando-se os conflitos entre essas instâncias e ampliando-se a influência e os controles do Executivo federal na condução das políticas educacionais em todo o território nacional.

\section{A reforma no campo educacional: as iniciativas do MEC}

$\mathrm{O}$ afă reformista do governo federal atinge fortemente o campo educacional mediante o desenvolvimento de inúmeros programas e projetos de natureza, abrangência e impactos diferenciados, em todos os níveis de ensino. A amplitude dessa intervenção na educação básica constitui matéria de divulgação da ação política governamental, principalmente do ministro Paulo Renato, como pode ser verificado no balanço das ações do Ministério da Educação, divulgado em 1999, no qual se destaca que "o marco institucional do ensino foi profundamente alterado, por meio de Emenda Constitucional e leis - principalmente a Lei de Diretrizes e Bases", e indica as intervenções consideradas prioritárias. ${ }^{3}$ No ensino fundamental, são várias as açōes nomeadas: 
- A criação do Fundo de Manutenção e Desenvolvimento do Ensino Fundamental e de Valorização do Magistério (FUNDEF), com a Emenda Constitucional no 14.

- A fixação dos parâmetros curriculares nacionais para a educação fundamental, infantil e indígena, referência para professores e para a seleção de livros didáticos.

- A avaliação prévia da qualidade do livro didático a ser adquirido e a ampliação de quatro para oito séries do ensino fundamental.

- A criação de um canal exclusivo via satélite para capacitação e apoio ao trabalho de professores e o envio de Kit tecnológico a 50 mil escolas (TV Escola).

- Envio de recurso federal diretamente às escolas por meio de associaçóes de pais e mestres, que administram o dinheiro (Programa Dinheiro Direto na Escola).

- Implantação do Programa de Aceleração de Aprendizagem para alunos com alta defasagem idade-série, atingindo, em 1998, 1.200 mil alunos.

- Desenvolvimento de um programa de informatização das escolas, com envio de 30 mil computadores e treinamento de 8 mil professores-multiplicadores.

- Municipalização da merenda escolar, com envio de recursos diretamente para mais de 4.500 municípios.

- Deflagração em 1988 da Campanha Toda Criança na Escola, visando a estimular a matrícula.

Esse conjunto de açôes vai incidir diretamente nas administrações estaduais, interferindo localmente na formulação e na condução das políticas educacionais das secretarias estaduais e municipais da educação. Aliás, esse caráter gerencial que assume a administração no governo FHC, e que se revela nos inúmeros projetos desenvolvidos pelos diversos ministérios, parece reeditar, com novas roupagens, pelo menos no campo educacional, o "projetismo" que caracterizava a ação centralizadora do MEC, no pós- $64 .{ }^{4}$ No período aqui focalizado, o MEC inaugura uma estratégia de intervenção, assumindo claramente a racionalidade de seu modelo gerencial.

Quanto ao ensino médio, como observa Cunha, este “(...) permaneceu fora da saraivada de antecipações legais da LDB que o governo desfechou desde 1995, somente sendo objeto de uma proposta de 
reforma curricular em 1997", o mesmo não ocorrendo com a educação profissional, "que foi alvo de um projeto de lei ( ${ }^{\circ}$ 603/96) bastante detalhado. Promulgada a LDB, em dezembro de 1996, esse projeto foi retirado, pois a interpretação do ministério era a de que suas principais diretrizes estavam contempladas no curto capítulo III da lei, sendo suficiente a normatização via decreto presidencial". ${ }^{5}$ Nessa perspectiva, pode ser visualizada a ação do MEC no conjunto de projetos voltados para o ensino médio e a educação profissional:

- Reforma do ensino médio, aprovada pelo Conselho Nacional de Educação, com vigência para 1999.

- Instituição do Exame Nacional do Ensino Médio (eNEM), aplicado pela primeira vez em 1998.

- Estabelecimento por decreto da Reforma do Ensino Técnico, que separa o ensino técnico do ensino médio e permite a complementação do ensino profissionalizante.

- Instituição de um programa de Expansão do Ensino Técnico, com financiamento do MEC e Ministério do Trabalho, apoiado pelo BID, visando a reequipar as escolas técnicas públicas e criar uma rede de escolas técnicas comunitárias, em parceria com municípios, entidades sindicais e associaçôes comunitárias.

Sem dúvida, a análise desse elenco de medidas permite verificar o vigor da iniciativa do Executivo federal no campo educacional nesse período. A sua efetividade, contudo, vai depender dos consensos obtidos entre outros atores no interior do próprio governo e no âmbito da sociedade capazes de impulsionar açóes concretas que favoreçam o alcance das metas propostas. Por se inserir nesse cenário, como uma entidade de caráter singular, cujos integrantes são dirigentes do Poder Executivo estadual, logo, integrantes da sociedade política, mas que atuam nos moldes de uma entidade da sociedade civil (Aguiar, 1992), o Conselho Nacional dos Secretários de Educação (CONSED) ${ }^{6}$ passa a desempenhar uma posição estratégica no projeto do governo federal. Com esse entendimento, o ministério vai procurar atrair o CONSED para o seu campo de interesse.

\section{O novo padrão de relacionamento instaurado entre o CONSED e o MEC}

Para compreender o alcance dessa nova composição de forças no campo educacional, é relevante situar a posição que o Conselho 
vinha adotando. Emergiu o CONSED no cenário nacional, nos idos de 1980, como um fórum de resistência dos titulares das secretarias estaduais de Educação ao centralismo praticado pelo Ministério da Educação. ${ }^{7}$ Em razão do posicionamento claramente de contestação às diversas medidas do governo federal direcionadas à educação básica, o CONSED afirmou-se entre as entidades da sociedade civil que procuravam interferir na formulação e execução da política educacional tendo como bandeira a defesa da democratização da educação pública de qualidade.

$\mathrm{Na}$ década de 1990, no entanto, com a mudança do quadro sociopolítico nacional, a posição contestatória do CONSED vai ceder lugar a uma conduta conciliatória e de parceria com o Ministério da Educação. Tal posicionamento fica evidente, na medida em que parece estar cada vez mais sintonizado com as políticas desenvolvidas pelo Ministério da Educação, como também em alinhamento com as orientações dos organismos internacionais. Reiteradamente os documentos da entidade e os pronunciamentos dos seus dirigentes enfatizam a compreensão de que as grandes transformações que vêm ocorrendo no plano mundial estão a exigir mudanças profundas nos sistemas educacionais. Contudo, não é comum nesses posicionamentos a explicitação das causas mais profundas que impulsionam tais mudanças. Com efeito, não se encontram espaços para análises e reflexões sistemáticas sobre a reestruturação produtiva, o esgotamento paulatino dos Estados nacionais e o delineamento de novas exigências daí decorrentes, e suas profundas repercussões no aparato do Estado. Esta talvez seja uma das razóes pelas quais, sem maiores questionamentos, são assimilados e aceitos os pressupostos e as implicaçôes das reformas promovidas pelo governo brasileiro, no período em foco, o qual as considera imprescindíveis para conduzir o país à modernidade.

Por outro lado, dada a configuração política que o caracteriza após as eleições de $1994,{ }^{8}$ das quais emerge fortalecido o governo federal apoiado pela maioria dos governos estaduais, o CONSED modifica, paulatinamente, sua conduta política, acata os postulados e as iniciativas governamentais, e, aos poucos, vai se tornando o parceiro principal do Ministério da Educação na operacionalização das medidas de política que emprestam uma nova configuração ao sistema educacional.

Este novo posicionamento é plenamente reconhecido pelos diversos escalōes do Ministério da Educação, a exemplo do que 
afirma a titular da Secretaria de Educação Básica, ao avaliar a ação do CONSED no referido período:

(...) Tendo o CONSED como interlocutor prioritário e principal articulador de suas políticas junto aos sistemas de ensino, o MEC tem submetido a esse conselho, em primeira mão, os seus principais projetos voltados para a educação básica, buscando sempre estabelecer previamente a parceria necessária para que tais iniciativas sejam executadas com êxito. (CONSED. Relatório de Gestão, p. 116)

De fato, a análise das relaçôes entre o CONSED e o MEC, no período aqui enfocado, mostra as mudanças ocorridas no padrão de relacionamento entre estas duas instâncias, até então vigente. Evidentemente, isso vai ocorrer dentro do quadro do novo federalismo que emerge da Constituição de 1988, que tem na descentralização política e financeira seu ponto alto. Dentro dessa nova ordem institucional e federativa, e atendendo ao receituário de organismos financeiros internacionais, o Governo FHC inaugura um padrão de gestão que restringe a responsabilidade da União na oferta dos serviços educacionais, remetendo-os aos demais níveis de governo ou ao setor privado. Isso se torna bem claro ao se analisar o programa de ação do ministro Paulo Renato que tem como um dos pressupostos para melhorar o ensino básico o "engajamento dos demais niveis de governo".

Nessa direção, novas estratégias são utilizadas traduzindo um novo padrão de relacionamento entre as esferas de governo e entre este e a sociedade civil. Tal processo pode ser visualizado claramente, em março de 1995, quando o presidente FHC lançou, cercado de todo o aparato da mídia, em um grande evento realizado no município do Rio de Janeiro, a campanha Acorda, Brasil! Está na hora da Escola!, cujo objetivo primordial era o de mobilizar a sociedade brasileira, "especialmente os segmentos formadores de opinião, em torno dos grandes objetivos da politica educacional" (MEC, 1997, p. 111). Ainda nesse mesmo ano, reuniu-se com todos os governadores dos estados e do Distrito Federal para "discutir e firmar um compromisso de realizar esforços conjuntos para expandir e melhorar a qualidade do Ensino Fundamental no pais" (idem, ibid.). A Declaraçãa do Torto, como ficou conhecido o compromisso então firmado, foi o ponto de partida de um processo que culminou com a aprovação pelo Congresso Nacional, exatamente um ano depois, da conhecida Emenda Constitucional no 14 (idem, ibid).

É importante ressaltar que, durante esse período de governo, a maior parte de políticas, programas e ações desencadeados pelo 
MEC, foi apresentada e discutida com os titulares das secretarias de Educação, no âmbito do Conselho, ou mesmo em reuniões com as equipes técnicas. De acordo com o ministro Paulo Renato:

(...) este diálogo permanente levou a um verdadeiro pacto entre os governos no sentido de assegurar a concretização dos objetivos e das metas comuns. Nesse contexto de amplo entendimento ficou claro o novo papel assumido pelo MEC como indutor e estimulador de políticas e programas implementados em parceria pelos estados e municípios. (CONSED, Relatório de Gestão, idem, p. 111)

$\mathrm{Na}$ pauta dessa ação conjunta sobressai a campanha desencadeada pelo MEC, Toda Criança na Escola, que mobilizou os esforços dos três níveis de governo e de várias instâncias da sociedade, com o objetivo de ampliar a matrícula, e que, segundo dados do Ministério, teria incorporado mais de 400 mil crianças que se encontravam fora da escola fundamental. Outras ações conjuntas podem ser vislumbradas no período, tais como: a descentralização da merenda escolar; a realização do Censo Escolar; o planejamento e a implementação do Programa Nacional de Informática na Educação (PROINFO) e, mais recentemente, a realização do Exame Nacional do Ensino Médio (ENEM).

Nesse contexto, o CONSED passa a ser um aliado importante, ao tomar para si a responsabilidade (entre outras) de articular a implantação do Fundo de Manutenção e Desenvolvimento do Ensino Fundamental e de Valorização do Magistério (FUNDEF), mecanismo que vai contribuir para alterar os níveis de responsabilidade das instâncias governamentais no que se refere ao financiamento do ensino público. É relevante para o MEC contar com o apoio do CONSED, sobretudo em um momento em que era alvo de críticas, então, dirigidas pelas entidades representativas dos docentes que se insurgiam contra o descumprimento do acordo feito durante a Conferência Nacional para Todos, ainda no governo de Itamar Franco. Esse apoio é destacado pelo ministro Paulo Renato quando afirma que:

(...) o CONSED tem sido o espaço privilegiado para essa articulação e integração das açôes governamentais, facilitando o diálogo e levando ao que estou chamando de pactuação, isto é, o consenso em torno de objetivos, responsabilidades e formas de atuação. É isto que caracteriza a modernização das relaçôes intergovernamentais na área da educação. (Idem, p. 112)

Convém assinalar que o CONSED não apenas apóia as medidas de políticas do Ministério da Educação como vai mais além, propon- 
do e formulando políticas, de forma conjunta, tendo papel determinante em sua operacionalização. A sua presença é tão forte no âmbito dos setores que tem poder de decisão no MEC que, até mesmo, o estabelecimento de um novo eixo na política educacional lhe chega a ser atribuído, como acentua a responsável ${ }^{9}$ pela política de avaliação deste órgão:

A presença atuante do CONSED estabeleceu um novo eixo para as políticas educacionais, que passa hoje pela articulação com os sistemas estaduais de ensino, tendo sido particularmente importante para fazer avançar o processo de descentralização. Este movimento, desencadeado pelas forças de oposição ao regime autoritário, ganhou maior impulso com a autonomia conferida aos estados e municípios pela Constituição de 1988. Mas foi sobretudo na gestão do ministro Paulo Renato Souza que a descentralização passou a ser uma diretriz das políticas do governo federal na área educacional. A colaboração do CONSED contribuiu de forma significativa para a consolidação deste novo perfil das políticas de educação. (Idem, p. 113)

Acompanhando o processo de descentralização, o governo federal investe nas propostas relativas à avaliação do sistema educacional. Nessa direção, o Instituto Nacional de Estudos e Pesquisas Educacionais (INEP) vai ser o responsável para desenvolver e implantar métodos e modelos avaliativos condizentes com o ideário de racionalidade que subjaz à reforma educacional. Ênfase vai ser dada aos exames nacionais de cursos, inclusive como uma das formas de responder às pressões dos organismos internacionais. ${ }^{10}$

Para criar um aparato institucional que desse suporte a processos de avaliação em larga escala, o MEC teria de contar com apoio político e estruturas técnicas capazes de viabilizar os programas. Nesse contexto, a participação do CONSED foi também decisiva como sugere a presidente do INEP:

(...) nos últimos quatro anos... sempre se mostrou receptivo e disposto a promover a efetiva participação e o engajamento dos sistemas estaduais de ensino no desenho e na implementação das reformas e das políticas educacionais. Este espírito de parceria se mostrou particularmente produtivo na relação entre o CONSED e o INEP. Sem o apoio dos estados, não teríamos avançado na construção de sistemas nacionais de avaliação - como o SAEB e o ENEM - e no desenvolvimento e na implantação do Sistema Integrado de Informações Educacionais (SIIED), que permitiu ao Brasil dispor de um eficiente processo de produção de estatísticas e indicadores, que cobre todos os níveis de ensino e subsidia a gestão educacional nas diferentes esferas 
administrativas. É preciso destacar ainda a importante contribuição do CONSED na elaboração do Plano Nacional de Educação apresentado ao Congresso Nacional. (Idem, ibid.)

Para conduzir o programa de modernização do Estado, o apelo à introdução das novas tecnologias de comunicação e informação (NTIC) no setor educacional também esteve presente. O governo Fernando Henrique Cardoso atribuiu grande importância a essa questão, chegando a ser criado, como já foi aqui referenciado, um órgão específico - a Secretaria de Educação a Distância com os programas de TV Escola e o PROINFO. Estas iniciativas do governo federal receberam apoio de primeira hora do Conselho:

A articulação com as secretarias, via CONSED, também respaldou a implementação de programas inovadores lançados pelo MEC na atual gestão, como a TV Escola, o PROINFo e Dinheiro na Escola. Ao constituir-se num verdadeiro espaço de aglutinação e mediação dos interesses dos estados, o Fórum de Secretários de Educação teve um papel ativo na discussão da Emenda Constitucional no 14 e na mobilização do apoio necessário à implantação do FUNDEF. (Idem, ibid.)

É importante ressaltar que esse apoio se estendia não somente em relação às diretrizes de política do MEC como à sua linha programática, portando-se o CONSED como o elemento-chave na busca de consenso e agente importante para as mudanças propostas, aspectos destacados nos depoimentos dos escalōes superiores desse órgão:

Sem tolher a liberdade atribuída aos sistemas de ensino, a atuação do CONSED favorece o estabelecimento de uma agenda comum, promove a cooperação técnica e garante o permanente intercâmbio de experiências. Funciona, portanto, como um elemento mobilizador e indutor das mudanças. (Idem, p. 114)

Tendo o CONSED como seu interlocutor prioritário e principal articulador de suas políticas junto aos sistemas de ensino, o MEC tem submetido a esse Conselho, em primeira mão, os seus principais projetos voltados para a Educação Básica, buscando sempre estabelecer previamente a parceria necessária para que tais iniciativas sejam executadas com êxito. (Idem, p. 116) (...) a colaboração do CONSED e das Secretarias de Educação, como órgãos executores das políticas educacionais, foi de grande importância para a implantação das ações prioritárias lançadas pelo MEC na gestão do ministro Paulo Renato, dentre as quais se destacam: o Programa Toda Criança na Escola; a produção e ampla disseminação dos Parâmetros Curriculares Nacionais (PCNs); a reestruturação do Programa Nacional do Livro Didático (PNDL); e o apoio ao Programa de Aceleração da Aprendizagem. (Idem, ibid.)

Educ. Soc., Campinas, v. 23, n. 80, setembro/2002, p. $72-89$

Disponível em <http://www.cedes.unicamp.br> 
Convém assinalar que o governo considera a importância estratégica do CONSED para o estabelecimento de condições favoráveis à implementação das políticas em todo o território nacional. No jogo político, contar com estruturas de apoio fortes nos estados, em um país de dimensōes continentais como o Brasil, é um trunfo relevante para não só concretizar as medidas que vão sendo adotadas como também enfrentar as críticas das correntes adversárias.

Neste ponto, é interessante observar que a própria natureza das políticas da educação favorece um certo consenso e a acolhida das propostas por parte dos diversos segmentos sociais. Basta lembrar que a educação aparece como um bem que todos defendem, inclusive os neoliberais. Aliás, sobre este "consenso", é oportuno atentar para a análise de Azevedo (1994), quando afirma que:

em relação à política educacional, pode-se dizer que o vírus neoliberalizante não a contagia na mesma proporção em que atinge outras políticas sociais. A educação é tida como um dos setores pioneiros de intervenção estatal, uma das funções permitidas ao "Estado Guardiāo". Friedman, por exemplo, não inclui a educação entre as 14 áreas as quais julga inadmissível serem subsidiadas pelos recursos públicos. Muito ao contrário, a ampliação das oportunidades educacionais é considerada um dos fatores mais importantes para a redução das desigualdades (Friedman, 1984, p. 157-158)

Muito embora, como ainda esclarece Azevedo, seja postulado um outro tratamento para o sistema educacional, compartilhando responsabilidades com o setor privado.

Essa expectativa positiva para com a educação constitui um aspecto que não passa despercebido nas avaliações feitas por dirigentes do Executivo federal em relação à conduta do CONSED:

Um dos resultados mais expressivos alcançados pelo CONSED na atual gestão foi ter conseguido manter um equilíbrio entre o papel político que lhe cabe exercer na defesa dos interesses educacionais dos estados e uma função mais técnica, exercida por meio de discussão qualificada das políticas educacionais e de iniciativas que promovem o fortalecimento da capacidade gerencial das secretarias estaduais. Um CONSED politicamente forte também é um fator de estabilidade nas relações intergovernamentais, que são próprias do sistema federativo. O nível de diálogo e entendimento mantido hoje entre as três instâncias do governo na área educacional - representadas pelo MEC, CONSED e UNDIME - têm sido determinantes para sustentar os avanços de políticas para a melhoria da escola pública. (Idem, p. 114) 
Sem abrir espaços para o debate dos pressupostos e das diretrizes que orientam a reforma educacional, o CONSED contentase em apresentar, pelo menos, três argumentos para justificar este apoio às políticas ministeriais. O primeiro é que os diversos segmentos da sociedade anseiam por mudanças na escola; segundo, que a educação tem um valor estratégico para o desenvolvimento do país; e, por último, que a educação, pela primeira vez, está sendo ponto de destaque na mídia. Considera que as mudanças já observadas na área educacional "estão sendo impulsionadas, de um lado, pelas crescentes pressóes da sociedade que se mobiliza para exigir uma escola de melhor qualidade e, de outro, pelas ações coordenadas do Poder Público". Sobre este último ponto, enfatiza que o fortalecimento da cooperação e da parceria entre União, estados e municípios constitui um aspecto fundamental para garantir eficiência às políticas educacionais. Entende, também, ser indispensável ao êxito da reforma assegurar a participação de todos os segmentos ligados à questão educacional. Para o Conselho, a década de 1990 é a década das transformaçôes da qual é um dos seus principais protagonistas. (CONSED, Apresentação, p. 10)

Esta é, portanto, a visão que norteia a ação do CONSED nesse contexto, buscando promover a melhoria da qualidade da educação básica, com ênfase na gestão educacional e no regime de colaboração estados/municípios. Há o entendimento de que o CONSED, embora seja uma organização de direito privado, "legitima-se como fórum permanente de articulação e representação das secretarias dos estados e do Distrito Federal". Esta legitimação, avaliam seus dirigentes, credencia-o como um organismo público comprometido com a promoção dos interesses públicos (Idem, p. 11).

Vale notar que é exatamente nessa gestão, na qual se consolida o alinhamento com o MEC, que seus dirigentes, apoiados nessa suposta identidade de interesses, reiteram declaraçôes sobre o caráter público da entidade. Pode-se inferir a partir dessas manifestações que o público vem a ser entendido como sinônimo de governamental, pois o apoio incondicional é dado às políticas de reforma do governo federal. Desse modo, não surpreende que os interesses dos organismos internacionais também estejam contemplados, como evidencia depoimento de representante da Fundação Ford que, a convite desta entidade, pronuncia-se sobre a questão, centrando-se em uma avaliação da sua trajetória: 
Apesar dos avanços na democratização da política educacional dos estados a partir da criação do CONSED, em 1986, esta organização teve sempre suas ações tolhidas pela falta de uma estrutura permanente e pela ausência de planejamento de longo prazo. Era dependente da boa vontade e disponibilidade de funcionários da Secretaria de Educação e as suas atividades geralmente se restringiam às reuniōes irregulares do Fórum de Secretários e às negociações ad-hoc com o Ministério da Educação.

Este quadro começou a mudar rapidamente, a partir de 1994, com a ajuda do Instituto Paulo Freire e o apoio da Fundação Ford. Numa ação participativa e bem-sucedida, o CONSED mudou seus estatutos, reformulou sua estrutura interna e começou a traçar seus planos para instalar um escritório permanente em Brasília, iniciativa concretizada no último semestre daquele ano. Ao mesmo tempo, o CONSED começou a formar novas relações de parceria com outras instituiçóes, em torno de um programa de atividades prioritárias debatido e votado pelo Fórum de Secretários.

Talvez seja este último item que melhor representa a transformação do CONSED. Em vez de ser essencialmente um defensor passivo dos interesses dos estados em relação às iniciativas do MEC e dos legisladores, o CONSED propunha transformar-se numa instância pró-ativa de discussão e de estudos para tornar-se uma fonte de idéias e de liderança no debate educacional do país. A continuidade da política interna do CONSED de debruçar-se sobre a discussão educacional e de votar os seus próprios programas bianuais de ação mostra a sedimentação deste novo papel e a sua capacidade institucional de manter uma posição de destaque. (CONSED. Relatório de Gestão, 1996)

\section{Concluindo}

As avaliaçôes sobre a reforma educacional que vem sendo implementada pelo governo brasileiro não podem deixar de levar em consideração o importante papel desempenhado pelo Conselho Nacional dos Secretários de Educação (CONSED). É necessário verificar o grau e o nível de sua intervenção na arena decisória, considerando que não são somente os arranjos político-partidários que determinam a influência de que são portadores os membros do CONSED no jogo de interesses políticos. Ao participarem, em situações específicas, da definição das políticas educacionais e serem fiadores de sua implementação nos sistemas estaduais, os secretários e o próprio CONSED estão certamente contribuindo ou não para a concretização do direito à escola pública de qualidade para todos.

Neste sentido, as referências ao papel dessa instituição permitem exemplificar a pluralidade de atores e de alianças com que 


\section{tem contado o governo, mostrando-nos como mecanismos foram acionados para viabilizar o padrão restritivo e seletivo que assumiu a política educacional dos últimos sete anos.}

\section{Recebido e aprovado em julho de 2002.}

\section{Notas}

1. O Conselho Nacional de Educação - CONSED é um órgão colegiado de caráter normativo, deliberativo e consultivo, no âmbito educacional. No contexto nacional, poderá participar "de uma dinâmica política que ultrapassa o setor educacional, podendo se constituir em um espaço tanto de avanço na consecução das finalidades da educação brasileira como de retardo desses objetivos" (Cury, 2001, p. 45).

2. Analisei os principais documentos de política do CONSED e do MEC, produzidos entre 1995 e 1998, na tese de doutorado intitulada Gestão da Educação Básica no Brasil: a política do Conselho Nacional dos Secretários de Educação - CONSED, Universidade de São Paulo, 2000.

3. Cf. Educação: política e fatos sem propaganda.

4. Vale lembrar que, ao longo da década de 1970, e mesmo no início dos anos de 1980, o centralismo do Executivo federal reduz o poder de decisão das secretarias de Educação na política educacional, contribuindo, decisivamente, para que se tornem instâncias executoras de ações formais definidas no plano federal.

5. Cf. Luis A. Cunha, Ensino médio e ensino profissional, Tecnologia \& Cultura, Rio de Janeiro, СЕFET/RJ, ano 2, n. 2, jul./dez. 1998, p. 10-29.

6. Como lembra Cury (op. cit., p. 45-46): “A gestão da educação escolar no Brasil, de longa data, tem como um dos seus componentes os Conselhos de Educação, ao lado de ministros, secretários, diretores-gerais e outros nomes dados a ocupantes de cargos executivos. Tais Conselhos existem no Brasil desde o Império e adquiriram um grau variável de complexidade ao longo de muitos anos".

7. Cf. M. A. Aguiar, A política educacional no Brasil e papel do Conselho Nacional dos Secretários de Educação: uma questão polêmica, Educ. Soc., n. 42, São Paulo/ Campinas: Papirus/Cedes, 1992.

8. A cada eleição de governadores, são, em geral, indicados novos secretários de Educação, razão pela qual pode ser alterada a relação de forças no interior do CONSED e, eventualmente, modificada a sua conduta política ante as demais instâncias governamentais.

9. Trata-se da professora Maria Helena de Castro, Novo eixo para as políticas educacionais.

10. Como destaca Dias, referindo-se às fontes externas da avaliação: "Todas as ajudas do Banco a países em desenvolvimento e pobres são necessariamente associadas a avaliações ex-ante, intermediárias e ex-post. Por isso o Banco também está criando as competências locais em avaliação segundo seus critérios e necessidades. Portanto, ademais de uma função econômica de operações de empréstimo, o Banco cumpre também um forte papel ideológico. Evidentemente, a pedagogia da avaliação que estende aos países que se beneficiam de seus empréstimos tem as características do controle e da racionalidade econômica" (Dias, 2002, p. 34-35).

Educ. Soc., Campinas, v. 23, n. 80, setembro/2002, p. 72-89

Disponível em <http://www.cedes.unicamp.br $>$ 


\section{Referências bibliográficas}

ABICALIL, C.A. Plano decenal de educação para todos: um cenário para muitos atores. Em Aberto, Brasília, v. 13, n. 59, p. 37-41, jul./set. 1993.

AGUIAR, M.A. Supervisão escolar e politica educacional. São Paulo: Cortez, 1991.

AGUIAR, M.A. A política educacional no Brasil e o papel do Conselho Nacional de Educação: uma questão polêmica. Educ. Soc., Campinas, v.13, n. 42, 1992.

AGUIAR, M.A. Sistemas universitários na América Latina e as orientações políticas das agências internacionais. In: CATANI, A.M. (Org.). Novas perspectivas nas politicas de educação superior na América Latina no limiar do século XXI. São Paulo: Autores Associados, 1998.

AGUIAR, M.A. Parâmetros curriculares nacionais e formação do educador: a reforma educacional brasileira em marcha. Educ. Soc., Campinas, ano 17, n. 56, 1996.

AGUIAR, M.A. Gestão da educação básica no Brasil: a política do Conselho Nacional dos Secretários de Educação - CONSED. 2000. Tese (Doutorado em Educação) - Universidade de São Paulo, São Paulo.

ALVES, M.H.M. Estado e oposiçãa no Brasil: 1964-1984. Petrópolis: Vozes, 1987.

AMARAL SOBRINHO, J. O Conselho de Secretários de Educação. Brasília, DF: CEC/IPLAN, 1987

AMARAL SOBRINHO, J. et. al. Os padróes mínimos de qualidade dos serviços educacionais: uma estratégia de alocação de recursos para o ensino fundamental. In: Gomes, C.; Amaral Sobrinho, J. (Org.). Qualidade, eficiência e eqüidade na educação básica. Brasília, DF: IPEA, 1992. p. 71-97.

.ANDERSON, P. Balanço do neoliberalismo. In: SADER, E.; GeNTILI, P. (Org.). O pós neoliberalismo e o Estado democrático. Rio de Janeiro: Paz \& Terra, 1995. p. 54-63.

AZEVEDO, J.M.L. As políticas sociais e a cidadania no Brasil. Educ. Soc., Campinas, n. 28, 1987. 
AZEVEDO, J.M.L. A educação e a reforma do Estado. In: REUNIÃO ANUAL DO SBPC, 50., 1998, São Paulo. Anais... São Paulo, SBPC, 1998. CD-ROM.

AZEVEDO, J.M.L.; AGUIAR, M.A.S. Políticas de educação: concepções e programas. Estado da arte em política e gestão da educação no Brasil. Brasília, DF: ANPAE, 1999. (Série estudos e pesquisas, n.6)

BRASIL. Constituição da República Federativa do Brasil. 18. ed. atual. e ampl. São Paulo: Saraiva, 1998.

BRASIL. Lei n ${ }^{\circ} 9.424$ de 24 dezembro de 1996. Dispõe sobre o Fundo de Manutenção e Desenvolvimento do Ensino Fundamental e de Valorização do Magistério, na forma prevista no art. $60, \$ 7^{\circ}$, do Ato das Disposições Constitucionais Transitórias, e dá outras providências.

BRASIL. Lei de Diretrizes e Bases da Educação Nacional. Lei n ${ }^{\circ} 9.394$ de 20 dezembro de 1996. Estabelece as diretrizes e bases da educação nacional. Diário Oficial da União, Brasília, DF, 23 dez. 1996.

BRASIL. Ministério da Educação. Plano Decenal de Educação para Todos. Brasília, DF, 1993.

BRASIL. Ministério da Educação e do Desporto. Parâmetros curriculares nacionais. Brasília,DF, 1995. (documento introdutório).

BRASIL. Ministério da Educação e do Desporto. Planejamento político-estratégico: 1995-1998. Brasília, DF, 1995.

BRASIL. Ministério da Educação e do Desporto. Plano de desenvolvimento do ensino fundamental e valorização do magistério. Brasília, DF, 1995.

BRASIL. Ministério da Educação e do Desporto. Desenvolvimento da educação no Brasil. Brasília, DF, 1996.

BRASIL. Ministério da Educação e do Desporto. Programa Toda Criança na Escola. Brasília, DF, 1997.

BRASIL. Ministério da Educação e do Desporto. Secretaria de Ensino Fundamental. Conferência Nacional de Educação para Todos. Brasília, DF, 1994. 
BRESSER PEREIRA, L.C. A reforma do aparelho do Estado e a Constituição Brasileira. 1995. (Conferência no Seminário sobre Reforma Constitucional, patrocinada pela Presidência da República, janeiro de 1995, revisada em abril de 1996).

BRESSER PEREIRA, L.C. Crise econômica e reforma do Estado no Brasil. São Paulo: Editora 34, 1996.

BRZEZINSKI, Iria (Org.). LDB interpretada: diversos olhares se entrecruzam. São Paulo: Cortez, 1997.

CARNOY, M.; CASTRO, C.M. Como anda a reforma da educação na América Latina. Rio de Janeiro: FGV, 1997. p. 9-99.

COMISIÓN ECONOMICA PARA AMERICA LATINA Y EL CARIBE. Transformación productiva com equidad. Santiago: CEPAL, 1990.

COMISSÃO ECONOMICA PARA AMERICA LATINA E O CARIBE. Educação e conhecimento: eixo da transformação produtiva com eqüidade. Brasília, DF: IPEA/CEPAL/INEP, 1995.

CONSELHO NACIONAL DE SECRETÁRIOS DE EDUCAÇÃO. Contribuições à formulação do programa de educação para o Governo Federal no período 1990-1994. Brasília, DF: CONED, 1990.

CONSELHO NACIONAL DE SECRETÁRIIOS DE EDUCAÇÃO. Relatório de Gestão: 10 Anos, Brasília, DF: CONED, 1996.

CONSELHO NACIONAL DE SECRETÁRIOS DE EDUCAÇÃO. Relatório de Gestão: 1977/1998. Brasília, DF: CONED, 1999.

CORAGGIO, J.L. Economia y educación: nuevos contextos y estratégias. Santiago: CEPAL, 1992. (mimeo.).

CORAGGiO, J.L. Desenvolvimento humano e educação. São Paulo: Cortez, 1996.

CORAGGiO, J.L. Propostas do Banco Mundial para a educação: sentido oculto ou problemas de concepção? In: De Tommasi, L.; Warde, M.J.; Haddad, S. (Org.). O Banco Mundial a as politicas educacionais. São Paulo: Cortez, 1996. p. 75-124.

CUNHA, L.A. Ensino médio e ensino profissional. Tecnologia \& Cultura, Rio de Janeiro, v. 2, n. 2, p. 10-29, jul./dez. 1998. 
CURY, C.R.J. Os Conselhos de educação e a gestão dos sistemas. In: Ferreira, N.S.C.; Aguiar, M.A.S. Gestão da educação: impasses, perspectivas e compromissos. 3 ed. São Paulo: Cortez, 2001.

DE TOMMASI, L.; WARDE, M.J.; HADDAD, S. (Org.). O Banco Mundial a as politicas educacionais. São Paulo: Cortez/Ação Educativa/PUC-SP, 1996.

DIAS, J.D. Campo e caminhos da avaliação: a avaliação da educação superior no Brasil. In: Freitas, L. C. (Org.). Avaliação: construindo o campo e a crítica. Florianópolis: Insular, 2002. p. 13-62.

DINIZ, E.; AZEVEDO, S. (Org..). Reforma do estado e democracia no Brasil. Brasília, DF: UnB, 1997.

FONSECA, M. O Banco Mundial e a educação: reflexões sobre o caso brasileiro, cooperação internacional. In: DE TOMMASI, L.; Warde, M.J.; Haddad, S. (Orgs.). O Banco Mundial a as politicas educacionais. São Paulo: Cortez, 1996. p. 229-252.

FONSECA, M. O Banco Mundial e a gestão da educação. In: OliveIrA, D.A. Gestão democrática da educação: desafios contemporâneos. Petrópolis: Vozes, 1997. p. 46-63.

LAUGLO, J. Crítica às prioridades e estratégias do Banco Mundial para a educação. Cadernos de Pesquisa, São Paulo: Fundação Carlos Chagas, n. 100, p 11-36, 1997.

OLIVEIRA, D.A. (Org.). Gestão democrática da educação: desafios contemporâneos. Petrópolis: Vozes, 1997.

OLIVEIRA, J.B.A. União, estados a municípios e o sistema de ensino fundamental: atribuições a perspectivas. In: Gomes, C.A.; Amaral Sobrinho, J. (Orgs.). Qualidade, eficiência a eqüidade na educação básica. Brasília, DF: IPEA, 1992. p. 123-157.

VIEIRA, S.L. Neoliberalismo, privatização e educação no Brasil. In: Oliveira, R.P. (Org.). Politica educacional: impasses a alternativas. São Paulo: Cortez, 1995. p.27-55 (b).

WARDE. M.J. Políticas internacionais para a educação. Tempo \& Presença, São Paulo, v. 15, n. 272, p. 11-13, nov./ dez. 1993. 